\title{
A gestão da vida e da segurança pública no Brasil
}

\author{
Renato Sérgio de Lima, \\ Jacqueline Sinhoretto \\ \& Samira Bueno*
}

Resumo: O presente artigo busca, a partir da análise de uma série de evidências empíricas e de dados disponíveis, construir um panorama atualizado da área e, com isso, reforçar uma narrativa acerca da atual configuração da segurança pública no país que identifica os sentidos das fortes disputas pelo significado de lei, ordem e segurança pública, bem como interpreta os rumos e as opções institucionais em torno de como o Estado tem administrado os conflitos sociais da sociedade brasileira contemporânea. Narrativa essa que, em síntese, defende que há um forte hiato entre os princípios democráticos inaugurados com a Constituição de 1988 e as práticas institucionais das polícias, dos ministérios públicos e do Judiciário, que, paradoxalmente, delegam às polícias militares a gestão da vida da população e pouco avançam na sua valorização como princípio basilar a organizar suas práticas e procedimentos.

Palavras-chave: segurança pública, ordem pública, polícia militar, conflitos sociais, democracia.

\section{Introdução}

Todos imaginam saber o significado de "segurança pública", mas, ao buscar uma definição conceitual, Arthur Trindade Maranhão Costa e Renato Sérgio de Lima relataram as dificuldades analíticas à compreensão de múltiplas dimensões e desdobramentos que decorrem dos conceitos em uso nas ciências sociais. Segundo eles,

diferentes posições políticas e institucionais interagem para que segurança pública não esteja circunscrita em torno de uma única definição conceitual e esteja imersa num campo em disputas. Trata-se menos de um conceito teórico e mais de um campo empírico e organizacional que estrutura instituições e relações sociais em torno da forma como o Estado administra ordem e conflitos sociais (Costa \& Lima, 2014: 482).

E é em torno desse campo em disputas que o presente artigo pretende trabalhar.

Em textos anteriores, os autores deste artigo procuraram abordar o campo e suas disputas (Lima \& Sinhoretto, 2011; Sinhoretto, 2010), a partir de questões sociológicas construídas para investigar como, no contexto de desenvolvimento da democracia brasileira, são construídas as respostas públicas frente ao crime, à violência e ao pressuposto democrático do acesso à justiça e da garantia de direitos. O enfoque

\footnotetext{
* Renato Sérgio de Lima é doutor em sociologia pela USP, vice-presidente do Fórum Brasileiro de Segurança Pública, professor e pesquisador da Escola de Administração de Empresas de São Paulo/FGV e da FGV Direito São Paulo, coorganizador do livro Crime, polícia e justiça no Brasil (São Paulo: Contexto, 2014). <renato. lima@fgv.br>. Jacqueline Sinhoretto é doutora em sociologia pela USP, professora do Departamento de Sociologia e do PPGS da UFSCar, coordenadora do Grupo de Estudos sobre Violência e Administração de Conflitos.<jacsin@ uol.com.br>. Samira Bueno é doutoranda em administração pública e governo na Escola de Administração de Empresas de São Paulo/FGV, diretora executiva do Fórum Brasileiro de Segurança Pública. <sbueno@ forumseguranca. org.br>.
} 
comum está nas práticas institucionais das várias organizações que compõem o chamado sistema de justiça criminal brasileiro e sua relação com o projeto democrático regulamentado pela Constituição de 1988.

Nessa perspectiva, um marco da democratização política - a Constituição de 1988 - é parte de uma inflexão na relação entre polícias e sociedade, suscitada pela construção da democracia e pelas pressões sociais por novos modelos de política e de polícia. A Constituição significou uma mudança discursiva fundamental em relação aos mecanismos legítimos de controle social e do crime. Em texto anterior, Lima e Sinhoretto sintetizaram o argumento:

A democracia, apesar de todas as persistências de práticas violentas e autoritárias - dentro e fora das polícias - introduziu tensões no campo da segurança pública que, se não permitem a incorporação de consensos mínimos relativos às transformações no modelo institucional vigente, fomentam o debate sobre um modelo de ordem pública baseada na cidadania, garantia de direitos e acesso à justiça. Assim, elas parecem induzir, não sem contradições e resistências, mudanças de repertório e formulação de novos enunciados políticos, nos quais mecanismos de accountability e de governança sejam compreendidos enquanto instrumentos de eficiência democrática, vinculando o respeito aos direitos humanos às práticas operacionais das polícias na prevenção da violência e no enfrentamento do crime (Lima \& Sinhoretto, 2011: 130).

Na ordem democrática, os discursos de democratização e de defesa dos direitos humanos provocaram fraturas num modelo de ordem social até então hegemônico. Mas, diferentemente do que ocorreu na economia e em outras áreas de política social, a transição democrática não propiciou reformas mais profundas nas polícias, na justiça criminal e nas prisões. Arquiteturas institucionais e funções constitucionais mantiveram-se praticamente as mesmas, apesar de mudanças importantes na legislação infraconstitucional (que tanto ampliaram quanto restringiram direitos e garan-

1. Análises das ambivalências da legislação penal no período democrático encontram-se em Azevedo (2003). tias $^{1}$ ), transformações no papel do Ministério Público em direitos difusos e coletivos, no papel dos tribunais superiores, mudanças na composição das carreiras jurídicas, reformas no acesso à Justiça. Contudo, no que tange ao funcionamento ordinário de todo o aparato penal, é evidente a manutenção de práticas institucionais e de culturas organizacionais ainda balizadas pela legitimidade da ação violenta e discricionária do Estado, por formas de controle social que operam as desigualdades, por relações intra e interinstitucionais que induzem a antagonismos e falta de transparência ou participação social. Não há consenso de que a referência moral do sistema penal seja a defesa da vida, como estabelecido na Constituição, em seu artigo 5o.

O contexto institucional da democracia - ou da descontínua democratização do campo da segurança e da justiça criminal e suas disjunções - coincide historicamen- 
te com um fenômeno de também difícil definição conceitual e empírica, que é o crescimento do crime violento, cujas componentes são multivariadas, complexas e não coincidentes em suas causas, consequências e motivações subjetivas. Em todo caso, a aceleração das taxas de homicídio, e sua posterior focalização sobre estratos sociais delimitados, é um indicador importante da qualidade (ruim) da democracia e da descontinuidade da democratização do campo que procuramos descrever e analisar.

A coincidência histórica entre democratização (e seus processos descontínuos) e crescimento do crime violento (indicador da deterioração de direitos e garantias) tem sido pensada na forma de um paradoxo entre democracia e violência no Brasil atual, caracterizado por elementos específicos. De um lado, altas taxas de violência estão associadas a elevadas taxas de impunidade, o que rebate na baixa confiança nas leis e nas instituições; de outro, as instituições de segurança pública e justiça criminal, premidas pelas cobranças da mídia e da opinião pública, são regidas pela ideia de que algo precisa ser feito a qualquer custo para conter os "criminosos", abrindo margens para medidas de extremo rigor penal e, mesmo, para reforçar políticas criminais anacrônicas e discriminatórias.

Avanços eventuais na gestão policial e reformas na legislação penal têm se revelado insuficientes para reduzir a incidência da violência urbana, com evidência de falta de coordenação e controle. No âmbito do Congresso Nacional, há dificuldades para fazer avançar uma agenda de reformas requerida pela Constituição de 1988, que até hoje possui diversos artigos sem regulamentação, o que permite tanto zonas de sombra e insegurança jurídica como a prevalência de práticas institucionais forjadas nos períodos autoritários.

Para a segurança pública, o efeito dessa postura pode ser constatado na não regulamentação do artigo 23 da Constituição Federal, que trata das atribuições concorrentes entre os entes da Federação, ou dos parágrafos 7ำ e 8o, do artigo 144, que dispõe sobre os mandatos e as atribuições das instituições encarregadas em prover segurança pública. A ausência de regras que regulamentem as funções e o relacionamento das polícias federais e estaduais, e mesmo das polícias civis e militares, produz no Brasil um quadro de diversos ordenamentos para a solução de problemas similares de segurança e violência sem, contudo, grandes avanços em boa parte do território nacional.

Isso para não dizer que, por uma opção do nosso ordenamento jurídico, tanto segurança pública como ordem pública são conceitos empiricamente operacionalizados pelas instituições do sistema de justiça criminal, com especial ênfase às polícias, que vão manejá-los de acordo com o estrato populacional alvo de sua vigilância e das 
opções político-institucionais que as guiam. Não há na legislação, na jurisprudência e na doutrina brasileira uma definição clara dos limites e significados de tais conceitos e é na prática cotidiana que eles são utilizados para legitimar e justificar posições e ações (Lima, Silva \& Oliveira, 2013).

Desse modo, a história recente da segurança pública no Brasil tem sido marcada por demandas acumuladas e mudanças incompletas. Ganhos, como a forte redução entre 2000 e 2014 dos homicídios em São Paulo, tendem a perder força, na medida em que não estão lastreados na construção de normas técnicas, regras de conduta ou padrões capazes de modificar culturas organizacionais ainda baseadas na defesa do Estado e não da sociedade. Basta ver a forma como as polícias reagiram às manifestações de rua de julho de 2013, simultaneamente com excesso e omissão. É nítida a ausência de um projeto de governança das polícias brasileiras e de alinhamento das políticas de segurança pública aos requisitos da democracia e à garantia de direitos humanos. Há um hiato muito intenso entre pressupostos democráticos inaugurados pela Constituição Federal de 1988 e práticas institucionais que, no limite, subjugam o valor moral da vida ao papel socialmente imputado a quem é morto, seja pela ação das polícias ("vagabundo", "cidadão de bem", entre outras categorias nativas do imaginário coletivo brasileiro), seja como resultado dos diversos conflitos que permeiam uma sociedade rica e desigual, incluindo os de natureza criminal (Sinhoretto, 2014).

Não obstante esses movimentos, é também importante destacar as disputas travadas no campo para mudar a forma como as políticas públicas de segurança pública são formuladas e implementadas. Há uma série de novos atores em cena que estão travando batalhas pelo significado de lei, ordem e segurança pública e, nesse sentido, reconhece-se a multiplicidade de posições, correntes e tendências a influenciar o debate sobre o tema. Todavia, a gestão da vida e o controle social parecem estar delegados, até por pressões da sociedade que legitima respostas violentas por parte do Estado, às polícias militares, que adotam padrões operacionais pautados no confronto e na guerra, vitimando a população e os próprios policiais. Uma breve exposição do cenário pode corroborar tais questões.

\section{Um breve cenário do crime e da segurança pública}

Como anteriormente frisado, talvez o maior paradoxo da democratização brasileira seja a sua coincidência com o aumento vertiginoso dos índices de criminalidade, o que acirrou conflitos e aprofundou a desconfiança nas instituições democráticas. Ao analisar este cenário, Teresa Caldeira e James Holston (1999) afirmam que a sociedade brasileira vive uma democracia disjuntiva, já que a institucionalização da democracia política ampliou direitos políticos e sociais, mas não se traduziu na 
expansão dos direitos civis. Pelo contrário, a noção de cidadania foi sendo deslegitimada na medida em que ocorreu a emergência de uma noção de espaço público fragmentado e segregado, que convive cotidianamente com casos de injustiça, impunidade e violência. Neste sentido, Holston (2013) analisa o desenvolvimento da cidadania brasileira associando-a a dois fatores: de um lado, a incorporação ao regime político formal, e, de outro, a distribuição de direitos, práticas e significados entre a população, o que ocorreu de forma completamente desigual.

Ribeiro (2013) afirma que em uma democracia disjuntiva a dimensão civil dos direitos é limitada em três pontos:

1. impossibilidade de acesso às agências responsáveis por viabilizar a proteção e o exercício dos direitos civis (vida, igualdade, liberdade e propriedade), o que estaria relacionado à desconfiança dos indivíduos nas instituições estatais responsáveis por garanti-los e incentivaria a resolução privada de conflitos;

2. possibilidade de obtenção dos serviços limitada, porque em geral são caros e pouco compreensíveis a pessoas de baixa escolaridade;

3. diante da desconfiança e da incerteza, aumenta a probabilidade do uso ilegítimo dos poderes conferidos às instituições estatais por parte de seus profissionais.

Ainda, ao bloqueio do acesso à justiça e à efetividade dos direitos, deve-se acrescentar o tipo de solução e de aprendizado dos direitos que decorre do contato efetivo dos cidadãos com os serviços de justiça e segurança. No caso da justiça criminal e do contato da polícia com a população, a experiência é compulsória. No acesso desejado ou no contato compulsório, a percepção de que existe uma justiça para ricos e outra para pobres faz parte do senso comum (Sinhoretto, 2011).

Segundo Holston (2013: 401), a disjuntividade da democracia brasileira é responsável pelo surgimento de um tipo de cidadania insurgente, que reivindica para si uma nova formulação de cidadania, pensada no acesso a moradia, creche, segurança e demais tipos de serviços concebidos como universais. Em oposição, e também como consequência desse quadro, reforça-se a formulação de uma noção de cidadania diferenciada que enfatiza discursos de inclusão universal que, na prática, operam no sentido de inviabilizar a igualdade na distribuição de direitos e recursos. Neste cenário, a violência policial e a ineficiência do Judiciário configuram os mais poderosos instrumentos de reprodução dessa cidadania diferenciada, reproduzindo desigualdades e reforçando estereótipos segregacionistas. 
Isto porque tanto a polícia como o Judiciário são as instâncias que, por excelência, deveriam garantir a realização de todos os direitos para todos os cidadãos. Quando o Judiciário opta por dedicar-se prioritariamente aos direitos civis econômicos, em detrimento de uma atuação na proteção do direito à vida; ou quando a polícia incorre repetidamente em abusos e violências, tornam-se evidentes as falhas e descontinuidades do projeto democrático brasileiro, que não consegue superar a violência, a impunidade, o racismo e a corrupção; falha-se na garantia do Estado democrático de direito. E uma das maiores evidências dessa falência são, exatamente, as altas taxas de criminalidade com que convive a sociedade brasileira.

Se é possível afirmar que o Brasil melhorou de forma substantiva seus indicadores socioeconômicos nos últimos 30 anos, o quadro de violência indica a convivência com taxas de crimes letais muito superiores a outros países, o que nos coloca no triste ranking das sociedades mais violentas do mundo. Segundo levantamento recente produzido pelo Escritório das Nações Unidas sobre Drogas e Crime (UNODC), o Brasil possui 2,8\% da população mundial, mas acumula $11 \%$ dos homicídios de todo o mundo (UNODC, 2014). Isso significa que convivemos, nos últimos anos da década de 2010, com ao menos 50 mil homicídios anuais. Se considerarmos o cenário desde 1988, que reinaugura formalmente a democracia no Brasil, são mais de um milhão de vítimas de assassinato no país, majoritariamente jovens, pretos e pardos e residentes das periferias dos grandes centros urbanos.

GRÁFICO 1

EVOLUÇÃO DA TAXA DE MORTALIDADE

POR AGRESSÃO NO BRASIL (1988-2013)

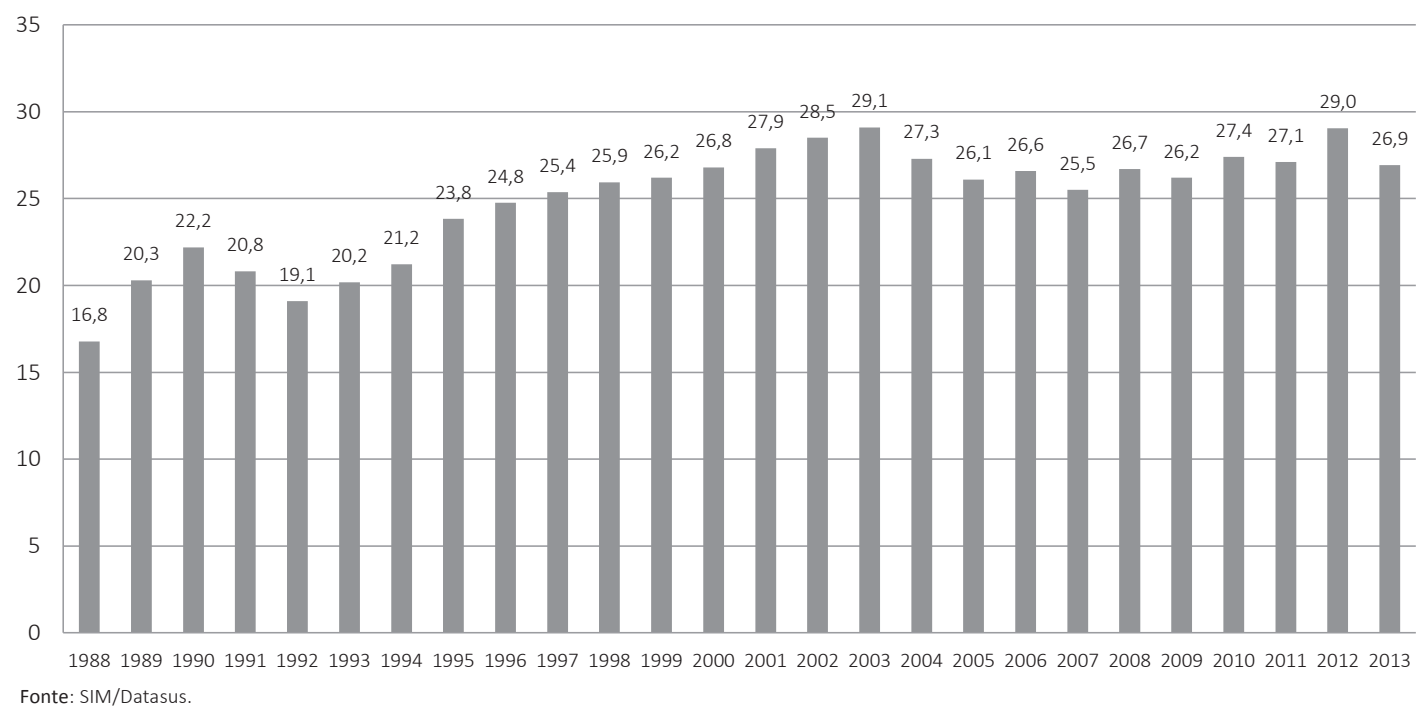


Este quadro endêmico de violência é reforçado pelas altas taxas de letalidade na ação policial, que produziram, em cinco anos (2009-2013), 11.197 mortes decorrentes de intervenções policiais e classificadas como confronto. Para se ter ideia da magnitude deste fenômeno, as polícias norte-americanas foram responsáveis pela morte de 11.190 pessoas num período de trinta anos, na evidência do abuso do uso da força letal entre os agentes policiais no Brasil.

GRÁFICO 2

EVOLUÇÃO DA LETALIDADE POLICIAL

BRASIL, 2009-2013

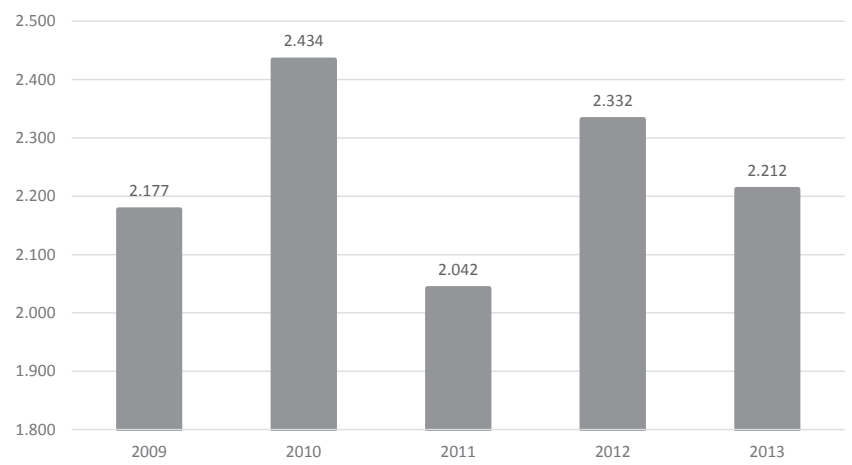

Fonte: Anuário Brasileiro de Segurança Pública, Ano 8, 2014.

Além das ocorrências registradas como confronto, preocupam também aquelas que escapam aos dados oficiais, conforme destacado por Bruno Paes Manso:

Só que esses números, apesar de dramáticos, ainda não são suficientes para clarear o debate da violência policial. Há as cifras negras. Resultados de práticas que não param de se repetir em grande intensidade desde os anos 1960, quando se formaram os famigerados esquadrões da morte do Rio e de São Paulo. Essas mortes no "caixa 2" são praticadas por uma minoria barulhenta de policiais, péssimos profissionais que prejudicam a imagem da corporação, atuando normalmente em carros ou motos descaracterizados. São integrantes de grupos de extermínio que matam para eliminar suspeitos ou para beneficiar seus próprios negócios criminais (Manso, 2014: 1).

Diante do grave quadro apresentado, a impunidade ainda reina absoluta em um país que naturaliza a barbárie. A maioria das corporações policiais continua a utilizar do registro de "auto de resistência" ou "resistência seguida de morte" nos homicídios praticados por seus policiais, o que supõem "exclusão de ilicitude". Segundo o artigo 23 do Código Penal, não existe crime se o agente o pratica em estado de necessidade, em legítima defesa ou em estrito cumprimento de dever legal/ 
2. Apenas a título de comparação, em 2002, a taxa de esclarecimento de homicídios na Alemanha foi de 96\%; no Japão, de 95\%; na Inglaterra, 81\%; no Canadá, 80\%; e nos Estados Unidos, de 64\% (Fórum Brasileiro de Segurança Pública (FBSP), 2014) no exercício regular de direito. Dessa forma, criminaliza-se a vítima antes mesmo da investigação, supondo-se a inocência do policial que praticou o homicídio em legítima defesa (Bueno, 2014). Embora essa nomenclatura tenha sido implementada como mecanismo para amparar legalmente o agente policial, ela tem cedido espaço para graves distorções, garantido a impunidade de homicídios praticados por policiais.

Entretanto, se analisarmos os casos de homicídios comuns, verificaremos que a situação não é diferente. Relatório produzido pela Estratégia Nacional de Justiça e Segurança Pública (Enasp), em 2011, estima que o índice de esclarecimento dos homicídios no Brasil varie entre $5 \%$ e $8 \%(F B S P, 2014)^{2}$. E, em acréscimo ao baixo esclarecimento destes delitos, destaca-se um cenário de baixíssima efetividade do sistema de justiça criminal, no qual, segundo pesquisa recente sobre os tempos médios dos processos criminais envolvendo homicídios dolosos (Ribeiro et alii, 2014), em uma cidade como Belo Horizonte, os poucos casos esclarecidos levam, em média, 3.403 dias (cerca de nove anos) entre o seu cometimento e o seu julgamento pelo tribunal do júri. Sob todos os parâmetros, o crime contra a vida tem gerado enorme disjunções no funcionamento do sistema de justiça criminal e de segurança pública e, por vezes, é relegado mais a um plano simbólico de sua gravidade do que em práticas efetivas para o seu enfrentamento e prevenção.

Os dados do sistema penitenciário reforçam evidências empíricas dessa baixa resolutividade dos crimes contra a vida: das 537.790 pessoas encarceradas no país em 2013, apenas $12 \%$ respondiam a crimes contra a pessoa (homicídio simples, homicídio qualificado, sequestro e cárcere privado), ou seja, pouco mais de 38 mil pessoas. Ao considerar o cenário de 50 mil homicídios anuais, este dado revela a ineficiência das polícias brasileiras. Mais do que isso, os dados do sistema penitenciário revelam também a ineficiência e a seletividade das polícias e do Judiciário: 60\% dos que cumprem situam-se na faixa etária entre 18 e 29 anos e são em sua maioria pretos e pardos, de baixa escolaridade; $40 \%$ da população prisional encontra-se em situação provisória, o que significa dizer que não foram julgados pela Justiça; e dentre os 322.151 julgados e condenados, a maioria (47,9\%) está presa por crimes contra o patrimônio, na evidência da centralidade que a dimensão patrimonial dos conflitos assumiu no país (Mapa do encarceramento, 2014). Da mesma forma, o Anuário brasileiro de segurança pública de 2014 indica que, dos 20.532 adolescentes cumprindo medidas socioeducativas no Brasil em 2012, último ano com dados disponíveis, apenas $11,1 \%$ correspondem a crimes violentos contra a vida (homicídios e latrocínios). Em síntese, prende-se muito mais para regular a circulação indevida de riqueza do que para prevenir violência e garantir vidas, pelas razões expostas no próximo item. 
GRÁFICO 3

Percentual de ENCARCERAdos, POR TIPO DE CRIME TENTADO/CONSUMADO (\%)

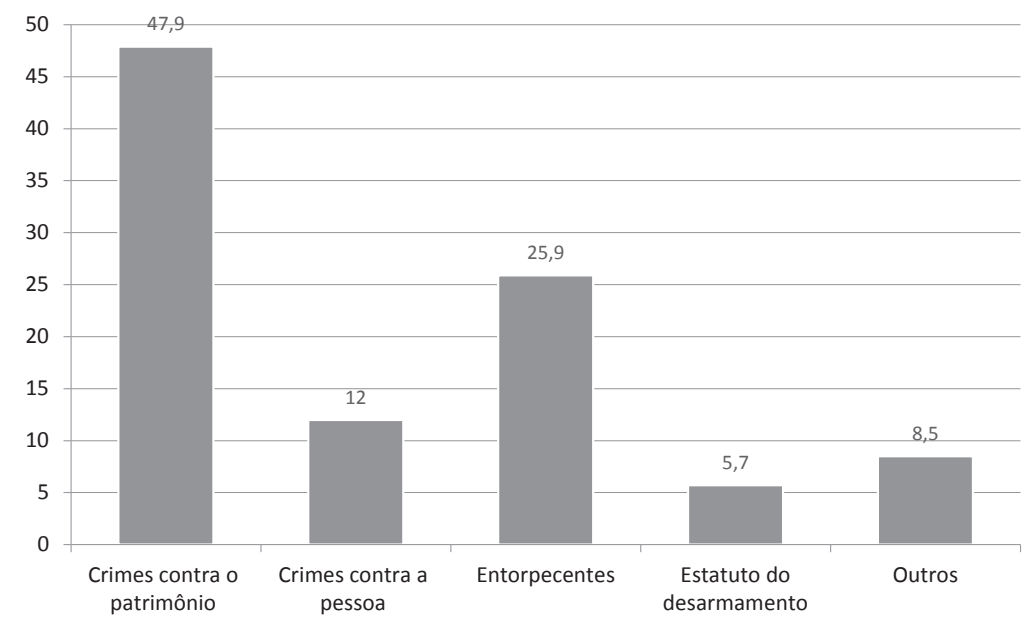

Fonte: Anuário brasileiro de segurança pública, Ano 8, 2014

O Brasil é também um dos líderes no ranking das sociedades que mais encarceram no mundo, perdendo apenas para os Estados Unidos e a China. Ou seja, prendemos muito e prendemos mal. Se aumentássemos a capacidade investigativa de nossas polícias, esclarecendo mais crimes e prendendo os responsáveis por crimes muito graves, como o homicídio, sem detrimento da investigação de outros crimes, certamente o Judiciário teria problemas extras, e seria ainda mais agravado o quadro do sistema prisional, que sofre atualmente com um déficit de 220.057 vagas (FBSP, 2014). Ou seja, se a polícia aumentar as prisões sem repensar a política criminal que retroalimenta a sua prática, o colapso das prisões será ainda mais dramático do que o atualmente apresentado.

O sistema penitenciário é ainda o espaço social de desenvolvimento de facções criminosas. Para não citarmos senão o exemplo paulista, cuja facção criminosa ficou conhecida em todo o país após paralisar o estado de São Paulo por uma semana, em 2006, recentemente estados como o Maranhão, Pernambuco e Santa Catarina têm sido objeto de atenção da mídia em função de rebeliões e decapitações dentro de unidades prisionais. Como agravante, a atuação do crime organizado não tem se restringido às prisões: essas organizações têm protagonismo nas periferias no que diz respeito ao provimento de serviços. No Rio de Janeiro, as milícias dominam diversos territórios por meio do provimento de serviços como fornecimento de gás e TV a cabo; em São Paulo, o Primeiro Comando da Capital (PCC) freta ônibus para os 
familiares dos encarcerados em dias de visita, além de cumprir papel fundamental na regulação e "pacificação" dos conflitos nas periferias.

Em suma, o Brasil apresenta um panorama complexo e perverso no que tange ao cenário da segurança pública. Os números aqui compilados indicam que convivemos com taxas que naturalizam mais de 53 mil crimes violentos letais e que são legitimados padrões operacionais de letalidade policial que vitimam ao menos seis pessoas por dia. E, num quadro mais amplo, alertam para os mais de 50 mil estupros registrados, para as constantes ameaças do crime organizado e para o crescimento dos roubos.

Como resultado, em termos econômicos, o país gastou cerca de $\mathrm{R} \$ 258$ bilhões em 2013 com os custos sociais da violência, que incluem estimativas com perdas de vidas e com despesas públicas com segurança e prisões. Ao mesmo tempo, várias são as evidências de que o dinheiro disponível pode não ser suficiente, mas não se consegue superar uma "lógica em uso", que resume o problema apenas à carência de recursos financeiros e/ou à falta de recursos como "armas e viaturas". Pouco se avança na discussão sobre a arquitetura institucional do sistema de justiça criminal e segurança pública e sobre o sentido e eficiência, em termos democráticos de controle do crime e garantia de direitos, das práticas institucionais vigentes. Em meio a esse movimento, as polícias, os governos, os ministérios públicos e o Poder Judiciário, insulados em seus projetos de corporação, não conseguem fazer frente aos desafios contemporâneos impostos pelo crime, pela violência e pela dinâmica de uma sociedade plural e democrática. Ou melhor, não conseguem traduzir o valor moral e jurídico da vida inaugurada pela Constituição Federal de 1988 em novas práticas e em novas políticas públicas, não obstante as pressões de um campo em conflito, acima destacadas.

\section{Analisando tendências da gestão do conflito}

Estudos que abordam a politização da justiça têm dado, em geral, menos destaque aos efeitos deste processo sobre as polícias em relação ao que já se acumulou na pesquisa sobre Ministério Público e Poder Judiciário. Contudo, como foi argumentado em um texto de Lima e Sinhoretto (2011), as corporações policiais também passam por um movimento de politização, com a introdução de temas de reforma, novos conteúdos e novas práticas e discursos. De um lado, as reformas gerenciais, iniciadas no final dos anos 1990, introduziram no debate das polícias a necessidade de padronização da formação profissional e o uso intensivo de ferramentas de gestão, tecnologia e planejamento. De outro, a judicialização da política passa cada vez mais por investigações criminais de governantes, líderes partidários, dirigentes de empresas públicas ou de órgãos da administração. De outro lado ainda, a política 
atual tem se feito também nas ruas, em manifestações populares de grandes e pequenas proporções, onde o papel das polícias militares no controle da ordem tem sido central.

Se o aumento da politização do Judiciário não significa uma alteração mais profunda nas formas judiciais de administração de conflitos (Sinhoretto \& Almeida, 2013), o mesmo é válido para as polícias. Os métodos de registrar, investigar e incriminar, as formas de administrar conflitos e de tratar os crimes, os acusados, os suspeitos, mudaram muito pouco, apesar de haver mudanças no contexto em que essas práticas se desenvolvem. O saber clássico da polícia é cada vez mais disputado por novos discursos e novos modos de fazer, que ainda são minoritários, mas já introduziram novos atores e novas demandas para o fazer policial, que colocam os modos clássicos em constante crítica.

Como exemplo, embora seja um movimento minoritário, cada vez mais críticas se acumulam sobre o papel de controle social de grupos exercido pela polícia: de um lado os movimentos da juventude negra questionando as mortes em decorrência da atividade policial e o encarceramento focalizados sobre esta faixa da população; de outro, os movimentos políticos da juventude discutem o papel da polícia na repressão às manifestações de rua. E cada vez mais esta crítica externa tenciona a produção do conhecimento nas academias de polícia, na formação superior de oficiais, na elaboração e no monitoramento de políticas de segurança. O intercâmbio de conhecimento produzido internamente à profissão e às corporações policiais se intensifica com os conhecimentos produzidos nas universidades e nas ONGs, e novos conhecimentos são apropriados por policiais com formação em ciências sociais e administração.

No texto anterior citado, foram abordadas as tensões internas de um campo em que a natureza da atividade é intrinsecamente discricionária, em constante relação com uma estrutura burocrática e hierarquizada. Também foram abordadas as tensões criadas a partir da posição liminar da polícia na administração de conflitos e na institucionalização da justiça criminal no Brasil, o que traz competição pela formação da verdade jurídica e cria oposições constantes entre as corporações e os grupos internos. Como se insistiu numa análise minuciosa dos conflitos e tensões internas no texto anterior, agora o foco está direcionado para a análise de uma tendência mais geral da gestão da violência no Brasil e sobre o lugar da polícia nesta gestão.

Sinhoretto $(2011 ; 2014)$ tem trabalhado sobre evidências empíricas que indicam a predominância de uma lógica da administração institucional de conflitos que produz um desinteresse sistemático na gestão do uso da violência e, no mesmo sentido, uma preocupação com a dimensão patrimonial dos conflitos. Trata-se de uma lógica 
de administração institucional de conflitos que se desenvolve no contexto de uma sociedade rica e violenta (mesmo que riqueza e violência distribuam-se de forma desigual). Com base em estudos realizados em serviços e postos de trabalho nas franjas do sistema de justiça e polícia, realizados por um número crescente de pesquisadores, nota-se a prevalência de uma preocupação minuciosa com a administração de conflitos ligados à circulação da riqueza - mesmo em suas manifestações informais - ao passo da baixa relevância atribuída à administração do uso da violência física e seu consequente impacto sobre a garantia da vida.

Juizados especiais, câmaras de mediação, serviços de conciliação, intervenções policiais de variadas naturezas desenvolvem soluções para os conflitos trazidos pela população aos serviços estatais, mesmo nos bairros mais distantes e de pouca infraestrutura institucional (o que evidencia a capilaridade desta lógica) que privilegiam o tratamento das dimensões patrimoniais dos conflitos, silenciando, se defendendo ou recusando o tratamento do uso da violência. Em geral, um problema que envolve circulação de recursos (pagamento de uma dívida, pensão alimentícia, questões ligadas ao consumo de bens e serviços, divórcio, relação de inquilinato, relações informais de trabalho e comércio, relações de vizinhança e familiares) pode ser administrado numa série diversificada de instâncias, por ritos processuais desde os formais até os mais informais. Existe o processo civil, a conciliação judicial, a mediação extrajudicial, a conciliação informal, todas formas de administração de conflitos que são operadas por múltiplos atores no campo, entre juízes, promotores, delegados, agentes policiais, advogados, defensores públicos, mediadores profissionais, mediadores e conciliadores leigos, estagiários e estudantes universitários, assistentes sociais.

A lógica predominante é a busca de um acordo que deve favorecer a circulação da riqueza e a economia dos meios de administração de conflitos. As polícias civis e militares participam ativamente desta lógica realizando a administração de conflitos, atendendo casos e realizando acordos, como já documentado pelos estudos da área. As polícias em geral não se negam a atender e a administrar casos que têm questões patrimoniais envolvidas. Ao passo que as demais corporações e instâncias defendem-se sistematicamente de tratar a dimensão violenta dos conflitos, isolando esta como uma atividade exclusiva das polícias e da justiça criminal. Até mesmo os juizados especiais criminais desenvolveram uma solução eloquente neste sentido que é a conversão da medida alternativa em cestas básicas. A manifestação de violência se equaciona na sua tradução em uma riqueza material que deve circular.

Chama especial atenção que nos serviços estatais de administração de conflitos mais capilares se verifique um esforço intenso para a gestão da economia informal ou da circulação informal de riqueza entre indivíduos e agentes econômicos. Nem 
sempre o interesse de gestão é a formalização das relações econômicas informais ou a realização de um controle tributário sobre a circulação econômica. A invocação dos agentes estatais para regular uma multiplicidade de conflitos se realiza de modo que a dimensão patrimonial seja sempre valorizada, ainda que nas microrrelações e nas regiões mais afastadas - traço de uma sociedade em que a riqueza circula de forma desigual, mas circula em toda parte.

Em contrapartida, o interesse de regulação da violência física não é tão evidente e não alcança a mesma capilaridade. Como exposto no item anterior, os homicídios ocorrem em taxas estrondosas, especialmente nas áreas urbanas mais periféricas e/ou nos aglomerados favelados. A intervenção policial produz um elevado número de mortos, inverossímil para os países democráticos e que não estão em guerra. Manifestações de violência são comuns nas relações interpessoais e nas relações entre a polícia e a sociedade. O tratamento destes conflitos é difícil de encaminhar, as vítimas de violência devem dirigir-se a serviços específicos, os procedimentos (laudos, tomada de depoimentos etc.) são demorados, as taxas de esclarecimento e punição muito baixas. A administração dos conflitos é intrincada, custosa, pouco eficiente, nada eficaz.

Embora se tenha partido da análise dos conflitos cotidianos para evidenciar a lógica de administração que privilegia a dimensão patrimonial dos conflitos em detrimento da regulação do uso da violência, a breve análise de casos mais complexos pode ajudar a compreender que ela está em toda parte no modo como se administra conflitos no Brasil atual.

Ao olhar a composição da população carcerária do país, observa-se que a maioria dos presos está sendo processada ou foi condenada por delitos de natureza patrimonial e não por crimes contra a vida. Praticamente metade dos presos no país responde por crimes patrimoniais, um quarto responde por crimes relacionados a drogas. Nos anos recentes, a participação dos crimes contra a vida ainda declinou entre os crimes que motivam prisões no país, de $12,8 \%$ em 2008 , baixou para $12,0 \%$ em 2013; os crimes relativos a drogas, por sua vez, aumentaram em $5 \%$ sua participação entre os crimes que motivam as prisões. Em alguns estados, esta situação é ainda mais acentuada: há cinco estados brasileiros em que a maioria dos presos responde por delitos de entorpecentes, estando sempre os crimes contra a vida em menor relevância. Nos estados mais ricos, observa-se uma participação ainda menor dos crimes contra a vida na composição do perfil dos presos (Mapa do encarceramento, 2014).

Isso significa que o sistema penal trabalha de forma cada vez mais aprimorada para encarcerar os acusados por crimes patrimoniais e de drogas, já que as taxas de 
encarceramento são crescentes em todos lugares do país. Enquanto a participação dos crimes contra a vida na produção do encarceramento declinou ao longo de anos mais recentes. Prende-se muito menos para fazer a gestão da violência do que para regular a circulação indevida de riqueza.

Outro exemplo que permite corroborar a construção do argumento está relacionado à administração dos crimes cometidos pelos agentes do Estado durante a última ditadura. À parte os processos políticos e institucionais que levaram à construção da Anistia, cuja análise não será possível neste momento, decisões mais recentes do governo federal e do Supremo Tribunal Federal sedimentaram uma situação que tornou possível indenizar economicamente as vítimas da repressão política, mas não tornou possível investigar e responsabilizar - muito menos punir - os indivíduos e as corporações que cometeram abusos e violações à vida e demais direitos humanos.

Por esse entendimento jurídico, a Comissão de Anistia do Ministério da Justiça já trabalhou para assegurar a indenização a mais de 40 mil pessoas que tiveram seus direitos fundamentais violados pela repressão política, numa atitude inquestionavelmente justa. Ocorre que indenizar economicamente foi mais fácil do que investigar e incriminar o uso da violência por parte dos agentes estatais que atuaram na repressão. Foi mais favorecida a dimensão patrimonial da justiça de transição no processo de democratização brasileiro do que a discussão política e criminal dos atentados contra a vida, tortura e tantas outras formas de violências cometidas durante o regime autoritário. Muito mais dificultada foi a responsabilização institucional das corporações envolvidas com a repressão: nunca foi possível realizar o expurgo dos agentes e a extinção das práticas que surgiram ou se fortaleceram com a repressão política.

Parece que mesmo quando se vai discutir a violência institucional e o alto grau de brutalidade das polícias e de toda a repressão estatal, a administração da porção patrimonial do conflito encontra mais consenso do que as reformas institucionais necessárias para que as violações aos direitos humanos não se repitam nunca mais. E elas se repetem.

Num caso de violência policial bastante conhecido em São Paulo, quatro policiais militares mataram em uma ação um jovem negro que dirigia um carro. Na apuração, o jovem foi identificado como Flávio, dentista, proprietário do veículo e filho de um policial militar. O caso gerou imensa indignação nos movimentos antirracistas de São Paulo e teve repercussão também nos quadros da Polícia Militar do Estado de São Paulo, com mudanças na formação dos policiais e na nomeação de oficiais negros para cargos mais prestigiados. No tratamento judicial do caso, a família da 
vítima recebeu primeiro a indenização financeira, em decorrência de um processo movido na justiça cível, e apenas posteriormente o crime foi a julgamento no tribunal do júri, de onde os policiais saíram condenados. Esta lógica se repete em vários casos de vítimas de violência policial que são tratados judicialmente. Apenas para mais um exemplo, a família do pedreiro Amarildo, morador da Rocinha, cuja morte por policiais teve grande repercussão em 2013, já conseguiu o reconhecimento judicial dos danos de eliminação do provedor da família e obteve a sentença de indenização, também antes de se conhecer o desfecho criminal do caso.

Diante da análise mais sistemática da administração de conflitos em serviços estatais capilares ou da breve análise de casos de violência institucional de grande repercussão, o que se vê de comum é o predomínio da lógica judicial de administrar a dimensão patrimonial dos casos em detrimento do interesse ou da capacidade de gerir o uso da violência. A análise progressiva do campo estatal de administração de conflitos aponta a ausência de relevância institucional em exercer a gestão da violência e dos crimes contra a vida.

Não se priorizam estratégias específicas em relação à prevenção da violência fatal e, sobretudo, as poucas ações levadas a cabo em vários estados (Pacto pela vida, em Pernambuco; Estado Presente, no Espírito Santo; entre outros) perdem intensidade em sua operacionalização quando, por exemplo, os governantes por elas responsáveis são substituídos, recolocando resistências e reforçando isomorfismos que impedem mudanças mais estruturais. Ou ainda, quando se fixam metas de crimes patrimoniais para justificar tais programas e, como visto no item anterior, são os autores destes últimos crimes que irão lotar as prisões e ganhar o protagonismo nas políticas de segurança pública.

Nisto, a polícia é o ponto mais visível onde se manifesta a contradição de uma sociedade que reluta em aprofundar a sua democracia, introduzindo barreiras à extensão de direitos civis a todos os grupos sociais. Por trás dessa constatação aparentemente óbvia, encontra-se uma das mais duras batalhas em torno de como administrar conflitos e, em decorrência, de como definir categorias que tornem possível pensar no enfrentamento da violência e de práticas criminosas a partir de novos enquadramentos e do ordenamento democrático inaugurado em 1988.

Nesse sentido, a tentativa de apresentar aqui uma discussão sobre a questão da segurança pública teve o objetivo de ajudar-nos a identificar alguns dos elementos que tornam esse sistema impermeável às mudanças exigidas por uma sociedade democrática e, ato seguinte, políticas públicas que busquem neutralizá-los ou, ao menos, mitigá-los. 
Por esse raciocínio, o significado fundamental dos dados e discussões compiladas neste texto é que elas traduzem, em primeiro lugar, uma enorme dificuldade de a sociedade brasileira desvencilhar-se de suas históricas estruturas autoritárias e violentas e deixar que o cidadão usufrua de amplos direitos, com liberdade, participação e acesso à Justiça, tal como previsto no nosso marco legal. Em segundo lugar, vencer o desafio político-institucional implica na aliança entre medidas incrementais com foco no ensino, na gestão e na modernização tecnológica do Estado; e a efetivação de uma agenda de reformas estruturais, que não sejam apenas de natureza legal.

\section{Novos atores e uma agenda em aberto}

E é em torno desta aliança que muitas energias têm sido depositadas no país nos últimos 15 anos, que marcam também uma inflexão nos debates acerca das estratégias de controle do crime e do modelo de segurança público brasileiro. Isto porque se, nas décadas de 1970 e 1980, os movimentos sociais e a Igreja surgiram como atores importantes no processo de redemocratização, reivindicando direitos e lutando contra a violência de Estado, a partir da década de 1990 estes atores perdem centralidade e a sociedade civil organizada passa a exercer protagonismo por meio de outro tipo de relação com o Estado e com a população. A estratégia de ação deixa de ser exclusivamente na chave do enfrentamento e da denúncia, e a possibilidade de modernização começa a se desenhar a partir da associação com a academia e na prestação de serviços para o governo.

A partir de meados dos anos 2000, no entanto, uma conjunção de fatores parece alterar o modo como os diversos atores do campo interagem, dando origem a uma nova gramática. Dentre estes fatores destacamos: o reconhecimento, por parte da sociedade civil organizada, de que sua estratégia de ação não surtiu os efeitos desejados; o protagonismo que as universidades passam a assumir nos debates de política pública, processo muito influenciado pelos editais de pesquisa financiados pelo governo federal e pelo Programa das Nações Unidas para o Desenvolvimento (Pnud); o ressurgimento de segmentos do movimento social, tais como o movimento negro, especialmente as lutas da juventude negra, ou os movimentos de vítimas da violência policial, que pressionam as pautas da sociedade civil organizada, provocando mudanças nas relações com o Estado e, mais especificamente, com as polícias.

E é neste ínterim que parece se desenhar um movimento que pensa reformas substantivas no campo da segurança pública, a exemplo do que ocorreu a partir da década de 1970 com o movimento sanitarista. No caso da saúde, o movimento sanitarista, formado por profissionais da saúde, intelectuais e sociedade civil, foi responsável pela criação do Sistema Único de Saúde (SUS) e por profundas transformações no 
modelo de organização e atendimento à saúde. No caso da segurança, para além do reconhecimento de que o modelo vigente não é capaz de responder às demandas colocadas, observa-se uma coesão no discurso de um grupo formado por acadêmicos, sociedade civil organizada e, mais recentemente, policiais, que passam a vocalizar um movimento que pede reformas profundas no modelo de organização dos sistemas de segurança pública e justiça criminal. Um dos exemplos mais emblemáticos, mas não o único, deste movimento é o Fórum Brasileiro de Segurança Pública (FBSP) ${ }^{3}$, que assumiu protagonismo no discurso em torno das reformas no campo nos últimos anos.

Diante desta multiplicidade de atores e posições, o FBSP produziu pesquisa com 22 mil policiais de todo o país sobre modernização e reforma do campo da segurança. Questionados sobre o modelo de organização da segurança pública, 66,2\% dos policiais afirmaram que as carreiras policiais não são adequadas; $80,9 \%$ disseram que as polícias deveriam ser organizadas em carreira única; 75,8\% defenderam mudanças que integrassem o trabalho das polícias e $87,3 \%$ afirmaram que o foco do trabalho das polícias militares deveria ser reorientado para proteção dos direitos da cidadania.

Pesquisas produzidas por Sadek $(1995 ; 2004)$ também apontam para mudanças no que diz respeito à visão dos integrantes do Judiciário brasileiro, especialmente os magistrados. Segundo a autora,

é significativo o percentual de juízes que dista do tipo mais tradicional de magistrado - o que só se manifesta nos autos; vem se constituindo um "tipo" de magistrado "politizado", condizente com as potencialidades contidas no texto constitucional e no modelo institucional adotados após a Constituição de 1988 (Sadek, 2004: 47).

O Judiciário e as polícias civis e militares são algumas das instituições mais refratárias às mudanças e responsáveis diretas pela manutenção do quadro exposto neste artigo. Suas práticas não são informadas pelos pressupostos democráticos da Constituição Federal de 1988 e têm garantido a reprodução de desigualdades e a ineficiência no que diz respeito ao controle do crime e da violência, já que não foram capazes de se modernizar. Cabe-nos aqui resgatar o conceito de path dependence que, em linhas gerais, afirma que o desenvolvimento institucional das organizações é marcado por situações nas quais a escolha por determinada trajetória resulta em ocorrências de difícil reversão (Pierson, 2004). Neste sentido, quanto mais antiga for uma ordem institucional, mais resistentes às mudanças e mais incrementais serão as tentativas de mudanças.

No entanto, os movimentos capitaneados pela academia e pela sociedade civil acima relatados, e as pesquisas com os operadores deste campo parecem apontar para

3. Entidade constituída em março de 2006 com o objetivo de construir um ambiente de referência e cooperação técnica na área de atividade policial e na gestão de segurança pública em todo o país, formada por pesquisadores acadêmicos, policiais, representantes governamentais e da sociedade civil. 
um certo consenso de que o modelo atual falhou. O Brasil das últimas décadas não é o mesmo do passado, tanto do ponto de vista econômico como do ponto de vista social. As mudanças foram expressivas, mas o Judiciário e as polícias não foram capazes de acompanhá-las. Se as resistências às mudanças foram a tônica que ditaram os últimos 30 anos, parece que estamos diante de um momento no qual os próprios operadores reconhecem a necessidade de modernização. Isto porque chegamos a um ponto que, se as resistências e disputas corporativistas ainda são imensas, as tolerâncias com as deficiências do modelo têm colocado em risco as próprias instituições. Exemplo disso são os baixíssimos níveis de confiança com que contam Justiça e polícia de forma sistemática no levantamento produzido pelo ICJ/FGV.

Não se trata, portanto, de assumir aqui uma postura extremamente otimista no que diz respeito a mudanças no campo, mas de reconhecer que estamos muito próximos do colapso de um modelo que coloca em xeque instituições fundamentais para qualquer democracia. E, diante do quadro apresentado, fica a reflexão: estamos diante de uma janela oportunidade no que diz respeito a um movimento de mudanças na área? Ou, mais do que isso, estamos diante de uma conjuntura crítica, nos termos que postula Pierson (2004), na qual seria possível uma ruptura com a trajetória institucional assumida, na perspectiva da falência do modelo atual. Será que temos mais consensos do que dissensos?

Postulamos que se aparentemente vivemos uma conjuntura na qual acadêmicos, sociedade civil organizada e policiais parecem concordar que o modelo vigente não oferece as respostas públicas necessárias ao enfrentamento do crime e da violência, na prática, estamos diante não apenas de disputas corporativas em torno de "quem faz o que", mais do que isso, vivemos um momento no qual paradigmas dissonantes disputam a legitimidade do campo organizacional. E, em meio a esta disputa, cabe chamar a atenção para a inação do Judiciário e do Ministério Público na mudança de foco em relação aos homicídios e, com isso, o protagonismo das polícias militares na gestão da vida da população do país e, sobretudo, na definição não só da clientela do sistema de justiça criminal (já que quase todos os crimes elucidados o foram por intermédio de flagrantes) mas também de quem pode ser considerado "bandido" e quem pode ser "cidadão de bem", ou seja, de quem, pelo imaginário social e pelas culturais organizacionais vigentes, pode ser morto ou de quem merece viver.

Um exemplo desse argumento pode ser resumido na frase de um tenente da Polícia Militar do Estado de São Paulo, lotado nas Rondas Ostensivas Tobias de Aguiar (Rota) , unidade de choque reconhecida por sua disposição para o enfrentamento, no Facebook, que disse que "matar ladrão é nosso dever e função". E, ao invés de serem criticadas, frases do gênero ganham incentivos de parcelas da sociedade e não são condenadas, mesmo que moral ou simbólica, por parte das autorida- 
des. Por trás desse argumento, no limite, há um padrão que valoriza exatamente o enfrentamento, mesmo que existam "baixas" tanto entre os próprios policiais como entre os "bandidos". Se situações saírem do controle, o discurso vai imputar responsabilidades e atribuir mortes específicas a "desvios individuais de conduta", mas nunca a uma questão institucional. Além disso, ao manter esse padrão de enfrentamento, percebemos que há a manutenção da ideologia que vê a sociedade com desconfiança e como inimiga dos interesses do Estado, limitando canais de participação e de renovação de práticas e culturas organizacionais. E, em sentido inverso, não há um projeto político institucional ainda forte o suficiente para transformar o campo.

Em suma, se estamos diante de um momento em que mudanças podem ocorrer, e do relativo consenso entre os próprios operadores de que o sistema exige modernização e aperfeiçoamento, é baixo o grau de concordância em relação às causas da insatisfação e falência do modelo - agenda na qual cada uma das instituições, em um jogo de empurra, indica a outra como o problema: para a Polícia Militar o problema é a Polícia Civil e o Judiciário; para a Civil, a Polícia Militar e o Ministério Público, e assim por diante.

É baixo também o consenso a respeito de como deveriam funcionar cada uma das instituições e seus mecanismos de articulação. Contudo, mudanças já em curso devem tirar as instituições de sua zona de conforto - especialmente as polícias - dentre as quais podemos citar a aprovação do Estatuto das Guardas, que dá poder de polícia às guardas municipais e que resultou em uma Ação Direta de Inconstitucionalidade (ADI) ajuizada no Supremo Tribunal Federal (STF) pela Federação Nacional de Entidades de Oficiais Militares Estaduais (Feneme), que questiona a competência da União para legislar sobre guardas criadas no âmbito dos municípios; ou a Proposta de Emenda à Constituição (PEC) da presidente Dilma Roussef, que pretende dar maior protagonismo à União nos assuntos afeitos à segurança pública.

Diversas são as evidências de que forças de mudanças parecem atingir o Judiciário e as polícias. A questão posta é se estas mudanças serão capazes de garantir, de forma igualitária, segurança, justiça e cidadania para todos os brasileiros. Sem dúvida, o campo organizacional foi irradiado por evidências de que algo precisa ser feito. Todavia, a questão que norteia este artigo é a que retrata a atual correlação de forças no interior de tal campo e, a partir dela, indaga-se se há energias suficientes para converter vontade de mudança em efetivas ações de modernização democrática da área. Sociologicamente, há um profundo hiato entre práticas cotidianas e referências legais e morais, porém, para além deste fato, há um conjunto de situações que demonstram o quão complexo é conceber uma nova gramática e/ou narrativa que toma a vida como elemento constitutivo de um novo padrão civilizatório e de admi- 
nistração de conflitos sociais. O detalhe, contudo, é que, enquanto isso, uma pessoa morre a cada dez minutos no país e parecemos por demais anestesiados para nos comovermos com esse quadro.

Abstract: From the analysis of a range of empirical evidence and available data, this article seeks to build a current overview of the field and, thereby, to strengthen a narrative about the present configuration of public safety in the country that identifies the senses of strong disputes surrounding the meanings of law, order and public safety and that interprets the directions and institutional options around how the State has managed the social conflicts of the contemporary Brazilian society. This narrative, in summary, argues that there is a strong gap between the democratic principles inaugurated with the 1988 Constitution and the institutional practices of the police, the prosecutors and the judiciary, which, paradoxically, delegate to the military police the management of the life of the population and little advance in its recognition as a general principle to organize their practices and procedures.

Keywords: public safety; public order; military police; social conflicts; democracy.

\section{Referências}

AZEVEDO, Rodrigo Guiringuelli. Tendências do controle penal na modernidade periférica. As reformas penais no Brasil e na Argentina na última década. Tese (Doutorado) - Universidade Federal do Rio Grande do Sul (UFRGS), Porto Alegre, 2003.

BUENO, S. Bandido bom é bandido morto: a opção ideológico-institucional da política de segurança pública na manutenção de padrões de atuação violentos da polícia militar paulista. Dissertação (Mestrado) - Fundação Getúlio Vargas, Escola de Administração de Empresas de São Paulo, 2014.

CALDEIRA, Tereza; HOLSTON, James. Democracy and violence in Brazil. Society for comparative studies. Society and History, v. 41, n. 4, p. 691-729. 1999.

COSTA, Arthur Trindade Maranhão; LIMA, Renato Sérgio de. Segurança pública. In: LIMA, Renato Sérgio de; RATTON, José Luiz; AZEVEDO, Rodrigo Ghiringelli de (Orgs.). Crime, polícia e Justiça no Brasil. São Paulo: Contexto, 2014.

FÓRUM BRASILEIRO DE SEGURANÇA PÚBLICA - FBSP. Anuário brasileiro de segurança pública. Edição VIII. São Paulo, 2014.

- Impactos das escalas de serviço no desenvolvimento do trabalho da polícia civil. Relatório de pesquisa, edital "Pensando a Segurança". São Paulo: Ministério da Justiça; Pnud, 2014.

HOLSTON, James. Cidadania insurgente. Disjunções da democracia e da modernidade no Brasil. São Paulo: Companhia das Letras, 2013. 
LIMA, Renato Sérgio de; SINHORETTO, Jacqueline. Qualidade da democracia e polícias no Brasil. In: LIMA, Renato Sérgio de. Entre palavras e números: violência, democracia e segurança pública no Brasil. São Paulo: Alameda Editorial, 2011.

LIMA, Renato Sérgio; BUENO, Samira; SANTOS, Thandara. Opinião dos policiais brasileiros sobre reformas e modernização da segurança pública. In: Fórum Brasileiro de Segurança Pública.

LIMA, R. S.; SILVA, G. A. C.; OLIVEIRA, P. S. Segurança pública e ordem pública: apropriação jurídica das expressões à luz da legislação, doutrina e jurisprudência pátrias. Revista Brasileira de Segurança Pública, v. 7, n. 1, p. 58-83. São Paulo, Fev./Mar. 2013.

MANSO, Bruno Paes. E se a polícia federal entrasse de vez no combate aos grupos de extermínio no Brasil? SP no divã, Blogs Estadão, 2014. Disponível em: <http:// blogs.estadao.com.br/sp-no-diva/e-se-a-policia-federal-entrasse-de-vez-no-combate-aos-grupos-de-exterminio-no-brasil/>. Acesso em: 25 Nov. 2014.

MAPA DO ENCARCERAMENTO: OS JOVENS DO BRASIL. Secretaria Geral da Presidência da República, Brasília, 2014. Disponível em http <//juventude.gov.br/articles/ participatorio/0009/3230/mapa-encarceramento-jovens.pdf>.

PIERSON, Paul. Politics in time: history, institutions and social analysis. Princeton: Princeton University Press, 2004.

RIBEIRO, Ludmila Mendonça Lopes. A democracia disjuntiva no contexto brasileiro: algumas considerações a partir do trabalho das delegacias de polícia. Rev. Bras. Ciênc. Polít., n. 11. Brasília, Ago. 2013.

RIBEIRO, Ludmila Mendonça Lopes; COUTO, Vinicius Assis; VASCONCELLOS, Fernanda Bestetti; SOUZA, Jaime Luiz Cunha de; RATTON, José Luiz; FRANCO, Michele Cunha. O tempo do homicídio doloso em cinco capitais. Relatório de pesquisa. Carta Acordo SRJ; Pnud; Fundep 30543.

SADEK, Maria Tereza Aina. Poder Judiciário: perspectivas de reforma. Opin. Publica [online], v.10, n.1, pp. 01-62. 2004.

SINHORETTO, Jacqueline. A justiça perto do povo. Reforma e gestão de conflitos. São Paulo: Alameda, 2011.

Campo estatal de administração de conflitos: múltiplas intensidades de justiça. Anuário Antropológico, v. 2009, p. 109-123. 2010. 
- Reforma da justiça: gerindo conflitos numa sociedade rica e violenta. Diálogos sobre Justiça, n. 2, v. 1, p. 49-56. Brasília, Ministério da Justiça, 2014.

SINHORETTO, Jacqueline ; ALMEIDA, Frederico. Reforma do Judiciário: entre legitimidade e eficiência. In: SILVA, Felipe Gonçalves; RODRIGUEZ, José Rodrigo (Orgs.). Manual de Sociologia Jurídica, p. 197-218. São Paulo: Saraiva, 2013.

UNODC. Global Study on Homicide 2013. United Nations Publication, Vienna, 2014. 